\title{
Runstenen Sm 11 i Kårestad
}

\section{Per Stille}

Maria Lindgren har under sin tid som prefekt och ledare för svenskämnet vid Linnéuniversitet uträttat mycket. För mig som runolog har institutionens runutflykter varit glada upplevelser. Viktigare är ändå att många studenter $\mathrm{i}$ Sverige och världen har fătt lära sig grundläggande runkunskap i kursen Vikingarnas språk vilken har getts regelbundet vid Linnéuniversitetet. Vad kan passa bättre som hyllning än att beskriva runstenen i Kårestad som österut är den runsten som är närmast Lindåsen, Marias plats på jorden. Allra närmast är i och för sig västerut den runsten som står vid Växjö domkyrka, men avstånden skiljer sig inte alltför mycket.

Kårestad är den största byn i Furuby socken med inte mindre än 13 gårdar (Larsson 1979-1981:228). Storleken liksom namnet antyder en hög ålder. Av 1600-talskartorna ger Kårestad intryck av att ligga vid en relativt obetydlig väg i nord-sydlig riktning som ansluter norrut till vägen mellan Växjö och Dädesjö och söderut leder till Furuby och Hovmantorp. Hur vägarna har gått under äldre medeltid är naturligtvis svårare att säga. Numera går en stor, rak, öst-västlig väg mellan Växjö och Kalmar på behörigt avstånd från såväl Kårestad som Lindåsen.

Den 18 december 1666 utgick på Johan Hadorphs initiativ ett kungligt brev till alla biskopar och superintendenter att i församlingarna låta efterforska vilka fornminnen som kunde finnas. Detta arbete som oftast kallas rannsakningarna påbörjades under 1667 och kom successivt att redovisas till biskoparna och därifrån överlämnas till Antikvitetskollegiet. En andra omgång påbörjades 1689. År 1667 vittnade pastor Petrus Petri Lacander i Hovmantorp tillsammans med kyrkans sexmän, däribland Måns Larsson i Kårestad, om följande: "I Föreby Sochn uthi Korrestad finnes 2 stenar med Runestäfuer skriuit uppå huar, den eene stenen ståhr upp och är 6 allna höger offwan Jorden, den andre stenen ligge[r] Neder på Jorden och är 2 alna lång” (Stahre \& Ståhle 1992:147).

Kyrkoherde Lacander hade haft en lång väg till sitt pastorat. Han uppges vara född 1605, men skrevs in vid Uppsala universitet först hösten 1632 (Molin \& Wilstadius 1968:445). Möjligen är det samma person som våren 1637 också antecknas i Uppsala universitets matrikel. Vad han gjort före sin första inskrivning och mellan inskrivningarna är dunkelt. Fortsättningen var inte heller lysande. Prosten Harald Alzovius skriver i ett brev till Växjö domkapitel 1652: "min consanguinaeus Petrus Petri i Lakeberg, som varit vid akademien, har i många år setat utan bröd och lägenhet”. Sent i livet bättrade det sig när Lacander 1658 gifte sig med sin företrädares dotter i Hovmantorp 
och därmed också fick pastoratet. Han dog 1671 (Molin \& Wilstadius 1968:444).

Petrus Lacander var student i Uppsala medan Johan Bure, världens första runolog, fortfarande var verksam och kan naturligtvis ha skaffat sig någon uppfattning om runor. Intresset för och kunskapen om runor har säkert varierat mycket i prästerskapet, men åtminstone hans kollega kyrkoherden $\mathrm{i}$ Södra Ljungby Johannes Andreæ Dryander, död 1670, visade ett stort intresse och ger prov på sin beläsenhet vad gäller runor i sin rannsakning; så har han också kunnat inhämta kunskap ur sitt egna exemplar av Bures Runa-ABC (Stahre \& Ståhle 1992:125 f.). Det troligaste är väl att Lacander fått uppgifterna av Måns Larsson och sedan själv inspekterat stenarna, något som också de noggranna måttuppgifterna tyder på. Något egentligt skäl för att betvivla uppgifterna finns knappast.

Om nu runstenen varit känd redan 1667, hur kommer det sig då att den första uppteckningen är gjord först 1759 av Erik N. Bergmark (Kinander 1935:11 not 2)? Det finns inget entydigt svar på den frågan, men det finns uppgifter om omständigheterna kring de tidiga uppteckningarna av runstenar i södra Småland. För en stor del av dessa var Ulf Christofersson ansvarig. Han antogs som ritare vid Antikvitetskollegiet 1687 (Schück 1933a: 421) och signerar sina ritningar med UC. Hans första resa som runupptecknare gick till Västergötland samma år. 1689 skulle han ha kunnat vara med Daniel Hadorph på en tur till Småland, men på Hadorphs uppteckningar finns inte Christoferssons signatur. 1690 tillbringar han tiden mellan den 2 och 19 september genom att tillsammans med Johan Hadorph d.ä. läsa och rita av Gästriklands runstenar, inalles 12 stycken (Jansson 1981:14). Tydligen hann man med att rita av ungefär en runsten om dagen. 1691 reser Ulf Christofersson i Jönköpings län (Schück 1933b:154). Det gör han i sällskap med Johan Hadorph d.y. Resepasset för denne är utfärdat 23 juni 1691 (Schück 1933a:428). Resan kan vara föranledd av att som ovan nämnts en ny omgång av rannsakningar kommit antikvitetskollegiet till del 1690. Det är troligt att Christofersson har varit delaktig i planeringen av resan. I de inlämnade rannsakningarna finns marginalanteckningar av hans hand var någonstans runstenar skulle finnas. Han har också antecknat att han verkligen utfört avritningar och i fyra fall med angivande av årtalet 1691, Sm 55, Sm 77, Sm 93 och Sm 135'. I en inlämnad rapport anger han att han "afritat 43 hehle och halfva Runestenar" under resan 1691. 1692 i september och oktober reser han i Kronobergs län, samt i Östbo, Västbo och Mo. Ifrån denna resa säger han sig ha avritat 25 runstenar (Schück 1933b:154). Tydligen har han gjort denna resa ensam, för i det bevarade materialet är avbildningarna enbart signerade UC. Under fältresorna gjordes avritningarna troligen med blyerts och inte med bläck för att sedan vid hemkomsten renritas. Dessa renritningar (eller kopior av dem) användes vid förfärdigandet av träsnitt eller kopparstick, varvid papperskopiorna förstördes. De flesta av Christoferssons (och andra

$1 \mathrm{Sm}+$ signum $=$ inskrift i Samnordisk runtextdatabas. 
ritares) avritningar kom att skäras ut som träsnitt, men det dröjde till 1750 innan dessa trycktes i det första mer heltäckande runverket, Johan Göranssons Bautil (1750).

Christofersson säger sig alltså under resan 1692 ha upptecknat 25 runstenar, vilka tillsammans med hans övriga avritningar skulle finnas "Uthi En bok in quarto" (Schück 1933b: 154) men bara 18 av dessa kan återfinnas som träsnitt i Bautil. Vad har hänt med de övriga och vilka kan de ha varit? Christofersson har haft rannsakningarna att utgå ifrån, men han har under sin resa också avbildat ytterligare fyra stenar: $\operatorname{Sm} 8, \operatorname{Sm} 9, \operatorname{Sm} 40$ och en ornerad sten i Vederslöv. De runstenar som Christofersson har känt till från rannsakningarna men som inte finns $\mathrm{i}$ någon avritning är: en runsten $\mathrm{i}$ Ingelstad, två runstenar i Kårestad (Sm 11), en runsten i Ryssby (Sm 42), en runsten i Forsheda, två runstenar i Rydaholm (Sm 59 och Sm 60) och två runstenar i Öreryd (Sm 116 och Sm 117), sammanlagt 9 stycken. 7 av dessa (eller andra) runstenar bör han alltså ha ritat av utan att man gjort träsnitt av dem. Det är förargligt att tänka sig att två av dessa försvunna avritningar skulle kunna vara från Kårestad. Men det behöver ju inte vara så. Kanske var det så att den tillmätta tiden inte räckte till för att göra den avstickare som behövdes för att komma till Kårestad som ju inte låg vid en större landsväg.

Frågan om det funnits en eller två runstenar i Kårestad kvarstår. Helmer Gustavson (2008:143) ställer sig skeptisk till uppgiften att det rört sig om två stenar, men något starkt skäl för att betvivla kyrkoherden Lacanders uppgift finns knappast. Det finns dessutom ett särskilt skäl att anta en försvunnen parsten, och det är inskriftens formulering där resarna enbart omnämns som Klackes söner men ej vid namn. Namnen kan mycket väl ha stått på en försvunnen parsten. Det är inte vanligt med parstenar i det småländska materialet, men där finns ett antal möjliga exempel: Sm 135 med Sm 136, Sm 138 med Sm 139 och Sm 143 med Sm SVS1973;4. I de två första fallen står två stenar tillsammans, vilka av den anledningen kan antas ha utgjort ett monument. Det är dock inget annat i utseende eller innehåll som klart binder dem samman. I det tredje fallet är stenarna resta av samma person och utförda av samma ristare. I ytterligare fem fall antyds förekomsten av en parsten genom formuleringen 'stenarna', där dock den andra stenen är försvunnen: Sm 33, Sm 122, Sm 149†, Sm 151† och Sm 169. Sm 11 i Kårestad skulle alltså kunna utgöra ett nionde fall av denna företeelse i Småland att två eller fler stenar tillsammans utgör ett monument (jfr Stille 1999: 26 ff.). De två stenarna i Kårestad har enligt rannsakningarna skilt sig åt i storlek. En möjlighet är att den liggande stenen inte var fullständig utan att det redan under 1600-talet fattats en bit. Vart den försvunna stenen (eller bitarna av den) tagit vägen är svårt att säga. Stengärdsgårdar eller husgrunder är möjliga svar.

I Samnordisk runtextdatabas återges Kårestadstenen Sm 11 på följande sätt: · klaka $\times$ suniR $\times$ letu $\times$ hakua $\cdot$ stein $\cdot$ eftiR : - apur $\cdot \sin :$ auk $:$ eftiR : kala : auk : uikik : brypr : sina med transkription till normaliserad 
runsvenska: Klakka syniR letu haggva stcein ceftiR [f]aður sinn ok ceftiR Kala/Kalla/Galla ok Viking, brøðr sina.

Translittereringen utgår från Ragnar Kinanders (1935:59) läsning och beskrivning i Smålands runinskrifter. Helmer Gustavson undersökte och målade upp ristningen den 2 september 2006 (rapport till länsstyrelsen 11 november 2006). Hans läsning är i princip densamma som Kinanders även om han i högre grad påpekar att delar av flera runor är oläsliga på grund av vittring, något som jag bara kan instämma $\mathrm{i}$ efter att själv ha undersökt ristningen den 2 juli 2018. Det är inte så vanligt att större uppmärksamhet ägnas åt skiljetecken. Gustavson läser det sjunde skiljetecknet som två punkter, där Kinander redovisat en punkt, dock utan kommentar. Enligt min uppfattning består det femte skiljetecknet av ett kryss varav man kan urskilja en arm. Första skiljetecknet skulle möjligen ha kunnat vara två punkter, medan det är svårt att bestämma det sjätte skiljetecknets form.

Inskriften innehåller ett namn med osäker tolkning, Kali, Kalli eller Galli (Wessén \& Jansson 1940-1943:142). Samma namn verkar förekomma på den korsmärkta runstenen Sm 16 i Nöbbele, Östra Torsås, och Gustavson (2008:142) menar att det kan röra sig om samma person. Det är i och för sig inte ett orimligt antagande då runstenarna kan vara resta nära $\mathrm{i}$ tiden och antalet familjer som reser runstenar är begränsat. Om det är fråga om samma ristare är osäkert. Också namnet Viking återfinns på en närbelägen runsten, Sm 10 vid Växjö domkyrka. Här är det dock helt klart att det rör sig om två olika personer. Viking på Sm 10, som är en yngre sten, lever, medan Viking på den äldre stenen Sm 11 omnämns som död. Ristningarna Sm 11 och 16 bör vara gjorda någon gång under de första decennierna på tiohundratalet (Stille 2008:72 ff.). Det är en tid då enligt legenden den helige Sigfrid var verksam.

Kårestad har alltså varit en av de större byarna i Värend och utifrån runtexten också hemort för en betydande familj. Staffan Fridell (2015:39) hävdar att förleden i Konga härad är en inbyggarbeteckning *kurungar/*korungar 'kårestadsborna' med syftning på att Kårestad varit häradets tingsplats. 1379 ger ett gåvobrev vid handen att Ryd i Nöbbele socken senast då har börjat fungera som tingsplats. Fridell menar att det först är efter en senmedeltida ökad bebyggelse utanför centralbygden som Ryd kommit att få en central placering i häradet. Kårestad ligger dock i utkanten av det kända Konga härad, och en möjlighet man inte får bortse från är att häradsindelningen vid tiden då Konga fick sitt namn kan ha varit en annan än den vi känner från historisk tid. Vid tiden för runstensresandet bodde alltså en betydande familj i Kårestad, men från historisk tid känner vi inte någon sätesgård i Furuby. Martin Hansson (2001:257) menar att ett tidigare "runstensfrälse" under 1300-talet har kompletterats med ett "rusttjänstfrälse" och att huvudgården i somliga fall också flyttats från bygemenskapen. Någon gång har denna process ägt rum också i Kårestad. Var huvudgården i byn har legat återstår att ta reda på om möjligt. Runstenen står i dag vid en liten väg som leder upp mot byn en god bit ovanför en mindre bäck. Om Kårestad vid tiden för 
runstensresandet fortfarande fungerade som tingsplats och om Konga härad åtminstone till stor del omfattade det vi idag känner, så bör detta ha varit den viktiga vägen västerifrån för alla tingsbesökare. Det här kan ge en påminnelse om att även om många vägar har haft samma sträckning under mycket lång tid så kan ändrade förhållande göra att nya vägar behövs och gamla faller tillbaka i rang. Vad som har bestämt runstenens placering är inte alldeles självklart (jfr Stille 2015:142 ff.). Den står vid vägen upp till bybebyggelsen, men den står också i utkanten av ett gravfält med rösen (Kinander 1935:58). Dock vet vi inte om gravfältet var i bruk vid tiden för runstenens resning. Den lilla bäcken strax nedanför stenen är förmodligen alltför obetydlig för att stenen ska ha utmärkt en bro. Så det troligaste är nog ändå att stenen utmärker själva byn Kårestad.

Runstenen i Kårestad belyser en omvandling av det småländska samhället under vikingatid och medeltid. Den ger också anledning att begrunda villkoren för den tidiga antikvariska forskningen. Framtiden får utvisa om den eventuella försvunna runstenen någonsin påträffas.

\section{Litteratur}

Fridell, Staffan (2015). "Småländska ortnamnsstudier", Ortnamnssällskapets $i$ Uppsala årsskrift. Uppsala, s. 39-57.

Gustavson, Helmer (2008). "Katalog över runinskrifter i Kronobergs län”, Runor i Kronobergs län, Kronobergsboken 2008. Växjö, s. 113-227.

Göransson, Johan (1750). Bautil, det är: alle Svea ok Götha rikens runstenar, upreste ifrån verldenes år 2000 til Christi år 1000; för detta, efter glorvördigast $i$ åminnelse konung Gustaf Adolfs ok konung Karl XI:tes befallning afritade ok til största delen: uti former inskurne; men nu, efter vår allernådigaste konung Fridrich I:stas befallning ok riksens högloflige ständers begäran, med några anmärkningar utgifne af Johan Göransson. Stockholm, tryckt hos Lars Salvius, 1750. Stockholm. [http://urn.kb.se/resolve?urn=urn:nbn:se:umu:rara-86]

Hansson, Martin (2001). Huvudgårdar och herravälden. En studie av småländsk medeltid. Lunds studies in medieval archeology 25. Lund.

Jansson, Sven B. F. (1981). Sveriges runinskrifter. Bd 15. D. 1, Gästriklands runinskrifter. Stockholm.

Larsson, Lars-Olof (1979-1981). Småländsk bebyggelsehistoria. Växjö.

Kinander, Ragnar (1935-1961). Sveriges runinskrifter. Bd 4, Smålands runinskrifter. Stockholm.

Molin, Gösta Gideon \& Wilstadius, Paul (1968). Smolandi Upsalienses: Smålandsstudenter $i$ Uppsala på 1500-och 1600-talen. 2, 1626-1645: studenter från hela Småland samt Öland. Uppsala.

Samnordisk runtextdatabas. Institutionen för nordiska språk, Uppsala universitet. http://www.nordiska.uu.se/forskn/samord.htm

Schück, Henrik (1933a). Kgl. Vitterhets- historie- och antikvitetsakademien. 2, Antikvitetskollegiet, 1. Stockholm. 
Schück, Henrik (1933b). Kgl. Vitterhets- historie- och antikvitetsakademien. 3, Antikvitetskollegiet, 2. Stockholm.

Stahre, Nils-Gustaf \& Ståhle, Carl Ivar (1992). Rannsakningar efter antikviteter. Bd 3, Öland, Småland, Blekinge, Halland, Skåne, H. 1, Text. Stockholm.

Stille, Per (1999), Runstenar och runristare i det vikingatida Fjädrundaland. En studie $i$ attribuering. Runrön 13. Uppsala.

Stille, Per (2008). "Runstenar och runresare i Småland", Runor i Kronobergs län. Kronobergsboken 2008. Växjö, s. 72-83.

Stille, Per (2015). "Runstenarna i landskapet. En undersökning av vad placeringen av runstenarna i Tiohärad kan säga om resarna och deras budskap", Futhark 5, s. 137-149. 